\title{
User Perception on Electronic Payment Services in Kathmandu Valley
}

\author{
Satyendra Timilsina ${ }^{*}$
}

\begin{abstract}
There have been significant efforts in Nepal to increase the outreach of electronic payments services (EPS) in the last couple of years but the usage of these services has not seen significant progress. People are showing reluctance to accept the new form of payments as there are issues on users' acceptance of this new mode. There is a need to understand users' perception on EPS and act accordingly to improve the usage. This paper analyses users' perception on EPS from four aspects - perceived ease of use, perceived usefulness, perceived security and perceived trust. Results of the survey show that there are low average mean scores for security and trust when compared to perceived usefulness and ease of use. Respondents have cited accessibility of EPS as one of the major issues behind such a low usage. Most of the responses are found to be independent by gender, age group, income level and other attributes. Further, perceived usefulness and ease of use have higher effect on willingness to adopt EPS in future when compared to perceived security and perceived trust.
\end{abstract}

Key Words: Electronic Payments, User Perception, Perceived Usefulness, Perceived Ease of Use, Perceived Security, Perceived Trust, Technology Acceptance Model

JEL Classification: E42

* Research Scholar - Ph.D. (Economics), Andhra University, Visakhapatnam, India and Director, Nepal Rastra Bank, Email: satyendra@nrb.org.np

I would like to express my sincere thanks to my Ph.D. Research Advisor Prof Ch. Appa Rao, Department of Economics at Andhra University and Prof. Sai Kumar Chintalapudi, Visakhapatnam, India for their continuous support in conducting this research. I would also like to express my sincere gratitude to the Editorial Board and anonymous referees for their valuable comments that helped in enhancing the quality of this paper. 


\section{INTRODUCTION}

In the last couple of years, Nepalese financial sector has been aggressive in promoting Electronic Payments Services (EPS) in Nepal, but the usage of these services has not increased in the same pace1. Available statistics on digital and cash payments reveal that Nepal is still a cash fixated society, i.e. people are preferring cash to other means of payments for any form of transactions. According to a survey carried out by the United National Capital Development Fund (UNCDF) for Nepal Rastra Bank in a stocktaking exercise of retail payments in the country in 2017 , the transaction volume in a year across all six payment flows 2 stood more than Rs. 30.5 Billion, but only $0.23 \%$ were digitized (UNCDF, 2017). Payments data on usage of debit cards show that staggering share of card transactions are carried out in the ATMs, indicating that debit cards are predominantly used for withdrawing funds from ATMs. It is said that the share of electronic transactions carried out through card banking is less than 4 percent of total card transactions, indicating that almost 96 percent of the card transactions are carried out to withdraw cash through ATMs. This shows that there has been some gap between supply and demand of EPS in Nepal.

As the central banks all over the world show interest in safe and efficient functioning of payments and settlement systems (BIS 2005), there has been effort in making the payments system more accessible and trustworthy from Nepal Ratra Bank too, but no serious effort has been made in assessing the reason behind such a low usage of EPS in Nepal. As digital payments use technology, its usage cannot grow unless people are used to and comfortable with the new method of payments. It is therefore, there could be an issue on users' acceptance of these newly developed and introduced payments instruments. As electronic payments involve usages of technology, the issue of user acceptance comes in forefront while analyzing people's responses. General people are reluctant to change and this applies for changing their payments behavior from cash to non-cash mode too. People will start accepting the new mode of payments (through technological changes) only after they are convinced that it is beneficial from several aspects from cost to time, and their belief that adoption of new payment mode does not

According to Monthly Statistics published by Nepal Rastra Bank, there has been significant increase in the payments instruments in the recent years. For example, the number of customers registered for mobile banking increased at an annual average of 63 percent in the last six years. The growth of debit card issuance increased at an annual average 11.2 percent in the last six years. However, in the usages side, most of these instruments are not used at all or at very less proportion in digital payments.

2 In a payment matrix, payment flows within three participants in the economy - people, business and government. Therefore, there are nine payment flows: P2P, P2B, P2G, B2P, $\mathrm{B} 2 \mathrm{~B}, \mathrm{~B} 2 \mathrm{G}, \mathrm{G} 2 \mathrm{P}, \mathrm{G} 2 \mathrm{~B}$ and $\mathrm{G} 2 \mathrm{G}$. Of these nine payment flows, the study only looked into six payment flows: P2P, P2B, P2G, B2P, B2G and G2P. 
lead to compromising of safety and security of their financial transactions. And unless the new payments mode is widely accepted, the introduction of new product cannot yield desired outcome in the economy. Secure, affordable, and accessible payment systems and services help expand financial inclusion, foster development and support financial stability (World Bank, 2020).

There is a need to understand user's perception on EPS and act accordingly to enhance the usage of EPS in the country. The analysis of users' perception on the electronic payments services will not only help analyze the gap between demand and supply of EPS, but will also help policy makers in devising appropriate policy to make EPS more friendly to the users.

\section{LITERATURE REVIEW}

Users' perception on use of EPS can be studied by using several model including acceptance model such as Technology Acceptance Model (TAM), behavioral model such as motivation model (that looks at motivational intention) and Planned Behavior Model (that looks at beliefs and behavior) for accepting new mode of payments. The Technology Acceptance Model (TAM) was developed by F. D. Davis in 1989 and is useful in assessing peoples' preference for electronic mode of payments.

TAM argues that people's acceptance for a new technology depends on two variables; Perceived Usefulness as defined as the degree to which a person believes that using a particular system would enhance his or her job performance, and Perceived Ease of Use defined as the extent to which a person believes that using a particular system will be free from effort. Further, perceived usefulness depends upon the social influence process (known as subjective norms), job relevance, output quality and result demonstrability. Experience and voluntariness adds to the perceived usefulness and perceived ease of use to create the intent to use, which ultimately affects the usage behavior.

The Bank for International Settlement (BIS) in its consultative report on "General Guidelines for Payment System Development" released in May 2005, states, "At the end-user market level common characteristics demanded of payment instruments and services are i) high availability and choice of instruments, ii) information on the relative benefits, user costs and risks of different instruments, iii) low user costs, iv) interoperability among rival transaction networks for the same type of payment instruments and v) low legal risk and high degree of information security." This indicates that user's perception on the usage does not just depend on availability of choices of mode of payment, but also on the information regarding relative benefits, risk and user cost, interoperability and degree of information security. 
There are handful of studies on the factors affecting users' perception on the electronic payments services in the region. Amongst them, a study entitled 'Determinants of Customers' Acceptance of Electronic Payment System in Indian Banking Sector' carried out by Sanghita Roy and Dr. Indrajit Sinha used the Technology Acceptance Model (TAM). They used Perceived Ease of Use (PEOU), Perceived Usefulness (PU), Perceived Credibility (PC), Perceived Risk (PR) and Customer Attitude (CUAT) to analyze factors affecting E-payment acceptance. They concluded, "Among the factors, Perceived Ease of Use (PEOU) is found to be the most significant predictor. Conversely, customer attitude was found to have least significant effect on adoption of E-payment. Conversely, customer attitude was found to have least significant effect on adoption of Epayment."

A similar study entitled 'Mobile Banking and New Generation: An Indian Experience' was carried out by Dr. R K Uppal, in 2009 and used motivational model for studying the user's behavior. This study had ranked cost effective, convenient access, time savings, information accuracy, efficient services and security from 1 to 6 as motivational factors for the preference of E-channels in India.

Emrah Oney, Gizem Oksuzoglu Guven \& Wajid Hussain Rizvi (2017) studied the determinants of electronic payment systems usage from consumers' perspective by collecting data from a sample of 329 students at East Mediterranean University, Turkey. They used a model developed by Changsu Kim, Wang Tao, Namchul Shin, and Ki-Soo Kim in 2010 during their study entitled 'An empirical study of customers' perceptions of security and trust in e-payment systems'. This model considers perceived security and perceived trust as the determinants of Electronic Payments System usages. They discussed technical protection, transaction procedures, security statements and personal past experience with electronic payments system as the factors affecting the perceived security and perceived trust. The study found no evidence of a statistically significant relationship between transaction procedures and consumers' perceived trust and security in EPS use.

A study entitled "Technological Innovation in Banking User Acceptability and Payment Problems in Ghana: A Case Study of Zenith Bank Ghana Limited" carried out by Lawrence Yaw Kusi, Isaac Kwadwo Anim and Kwamena Minta Nyarku in 2015 found that the electronic banking reduces the costs of banking transaction. The report says, "E-banking reduces time involved in banking transactions and saves logistical resources...... Cash still remains the most popular retail payment instrument despite the increase in the introduction of electronic payment scheme in Ghana" 
Ogoti Elijah Sokobe, in 2015, concluded that age, level of education and relevant skills are the factors that affect the use of electronic payments. In his study entitled, "Factors influencing adoption of electronic payments by small and medium hotel enterprises at Kisli town, Kissi county Kenya" he found that youth adopt electronic payment faster than the older generation who take time to make decision on adoption of electronic payment.

The study entitled 'The development of e-payments and challenges for central banks in the SEACEN countries conducted by Lim Choon Seng Vincet in 2008 for the SEACEN Research and Training Centre in 2008, highlights the main factors affecting the developing of e-payments in the SEACEN Countries. It says, it is found that the development of technical infrastructure is considered the most important contribution to the development of e-payments. This is followed by user acceptance. Cost and profitability for operators is ranked third. The adequacy of the legal framework is ranked fourth among the factors and interoperability is ranked fifth. Easy entrance for operators, a proxy for enhancing competition, is ranked last among these factors.

There are two studies conducted by the Nepal Rastra Bank on the Electronic Payments Services in Nepal. First study, entitled "Promoting EPS in Urban Nepal" was carried out by the Payments System Department in 2017, whereas the second study entitled "Current Status, Potential and Challenges of using Financial Technology in Nepal" was conducted by the Research Department in 2018. Both of these studies, based on field survey, were internal studies of the concerned department and are not available for public consumption. The outcome of these studies has not been disclosed publicly.

\section{OBJECTIVES AND METHODOLOGY}

The general objective of this paper is to analyze users' perception on Electronic Payments Services in Kathmandu. The paper aims at testing the following hypothesis:

Null Hypothesis (H0): User perception on perceived ease of use, perceived usefulness, perceived security and perceived trust are independent by gender, education level, service type, age group and income group.

Alternate Hypothesis (H1): User perception on perceived ease of use, perceived usefulness, perceived security and perceived trust are not independent by gender, education level, service type, age group and income group.

The research is based on field survey and user's perception was collected on a five point Likert Scale. The questionnaire was developed with an aim to assess user's perception on several aspects of electronic payment services. For the purpose of 
analyzing user's perception an extended TAM model has been considered. In addition to perceived ease of use and perceived usefulness, perceived security and perceived trust has also been added. The concept of user for this research has been limited to individuals. The questionnaire thus aims at capturing people's perception while conducting a transfer transaction and/or an e-commerce transaction for internet banking and payments against purchase of goods and services.

The respondents of the filed survey were selected amongst those having a bank account. This criterion was chosen mainly because bank account is mostly required for performing an electronic banking services at retail level in Nepal. The samples thus selected were based on purposive and convenient sampling technique. The sample size of respondents was identified by using the following formula (Lwnga \& Lemeshow, 1991).

$$
\text { Sample Size }=\frac{Z^{2} P(1-P)}{D^{2}}
$$

Here, $\mathrm{Z}$ is the $\mathrm{Z}$-score value for desired confidence level, $\mathrm{P}$ is the true proportion, and $\mathrm{D}$ is the margin of error.

Assuming a 95 percent confidence interval, the $Z$ value is 1.96 . $P$ value, which represents the true proportion of those using EPS in Nepal, is not known and therefore has been assumed to be 0.50 . The margin of error has been assumed to be 10 percent. Based on these assumptions of 95 percent confidence level, true proportion of 0.5 and 10 percent margin of error, the minimum number of sample for the study is calculated to be 97 . The final sample of the study however stands at 101. The respondents were selected from different areas of Kathmandu valley. The sample has been analyzed from five categories; a) male and female for analysis of gender; b) private, public, self-employed and unemployed for service type; c) under SEE, SEE to plus two, plus two to Graduate and Above Gradation for education, d) 18 to 25 years of age, 25 to 40 years, 41 to 58 years, and above 58 years for age group and, e) low income (less than annual income of Rs. 100,000), moderate income (Rs 100,000 to 400,000), high income (Rs. 400,000 to 1,200,000) and very high income (Above Rs. 1,200,000) for income level.

The data was collected during the Month of November and December 2019.

The following is the conceptual framework of the Model under study. 


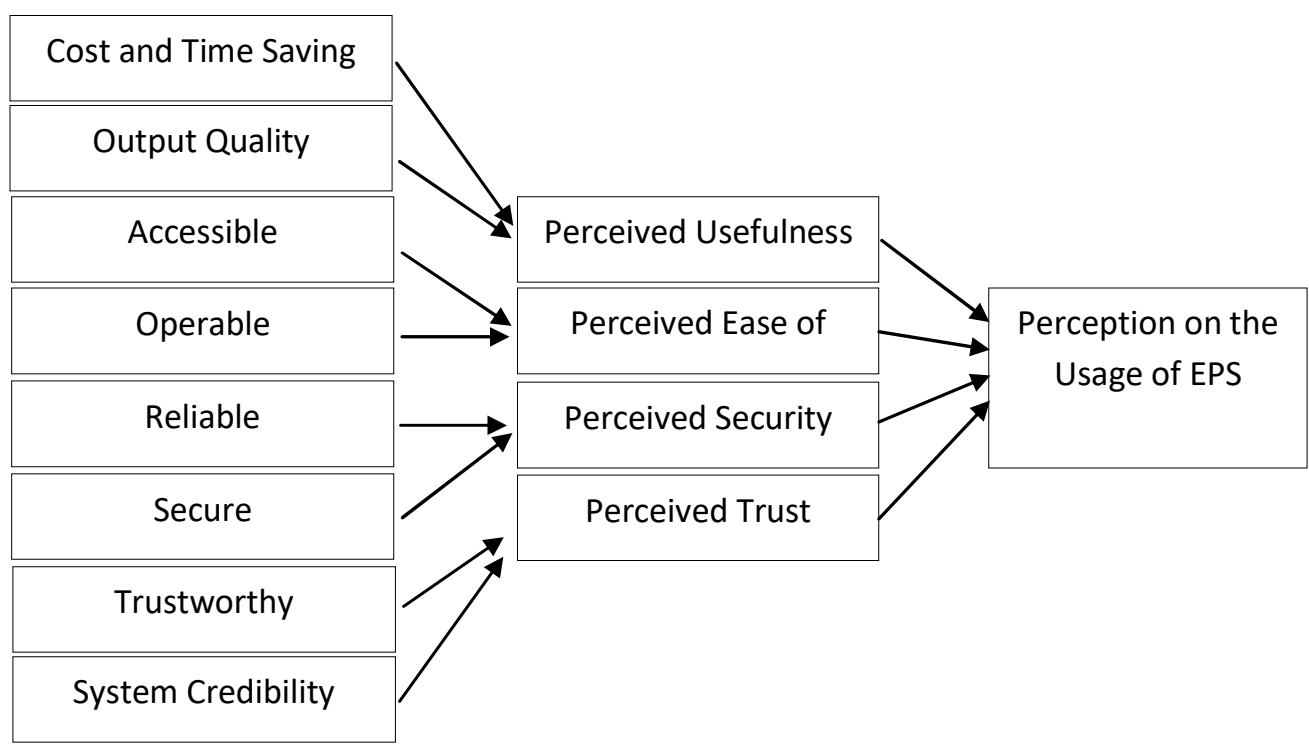

For the tabulation and coding of the data, Microsoft Excel 2016 was used and for the analysis of data SPSS 20 has been used along with the Microsoft Excel. Regarding the tools of analysis, descriptive statics that included mean scores and variances, Chi square test of independence, test of internal consistency and regression model has been used.

There are several techniques to analyze the impact of variables on the users' willingness to carryout EPS in future. There are no specific models that is widely accepted amongst researchers for this type of responses. Some researches (Oney et al. 2017, Park, 2009) on behavioral social science have used measurement models to analyze the impact, whereas others (Roy et al., 2014, Alireza et al., 2010 and Alenezi et al., 2010) have used linear regression model. There are suggestions for ordinal regression model as well for this type of research. This research uses multiple regression analysis model for the analysis. For the impact analysis, dependent variable has been assumed as Willingness to accept EPS and independent variables are assumed as use, easy, secure and trust.

The proposed regression model is:

$$
\mathrm{INT}=\beta 0+\beta 1 \mathrm{USE}+\beta 2 \mathrm{EASY}+\beta 3 \mathrm{SECURE}+\beta 4 \mathrm{TRUST}+\varepsilon
$$

Where: INT = customers' intention to accept EPS, USE $=$ consumers' perception of Usefulness of EPS, EASY = Consumers' perception of ease of Use of EPS, SECURE $=$ Consumers' perception on security of the EPS, TRUST $=$ consumers' 
perception of Trustfulness of the EPS and $\varepsilon=$ is the error term for any missing variable.

\section{RESULTS AND ANALYSIS}

The results from the empirical study is explained hereunder.

\section{Descriptive Statistics}

For the analysis of user's perception, responses were collected on eight items from the respondents on a five point Likert Scale. For the analysis, these eight items were grouped into four variables - usefulness, ease of use, security and trust. Users' perception on these four variables were collected separately again in five point Likert Scale. The summary of descriptive statistics on these eight items is presented below.

\begin{tabular}{|l|c|c|}
\hline \multicolumn{3}{|c|}{ Table: 3} \\
\hline & Descriptive Statistics on User's Response \\
\hline EPS helps in Cost and Time Savings & 4.65 & Std. Dev. \\
\hline Output Quality of EPS is good & 3.95 & 0.50 \\
\hline Accessibility of EPS is good & 2.12 & 0.48 \\
\hline Operability of EPS is good & 3.76 & 0.82 \\
\hline EPS is Reliable & 4.05 & 0.63 \\
\hline EPS is Secure & 3.88 & 0.41 \\
\hline EPS is Trustworthy & 3.99 & 0.41 \\
\hline EPS has System Credibility & 3.25 & 0.41 \\
\hline
\end{tabular}

The table shows that the average mean score (on 1 to 5 scale, 5 representing strongly Agree) of the accessibility of EPS is lowest with 2.12, with highest standard deviation. This indicates that one of the biggest hurdle on the usage of EPS in Nepal is low level of accessibility. Accessibility included, acceptance of digital payments by the vendors inside the country and availability of the services round-the-clock. Respondents expressed their reluctance to accept that the availability of EPS is good in the economy. The average mean score for reliability and cost and time savings remained above 4 while average mean score for credibility, security, trustworthiness, operability and output quality remained between 3 and 4 . These scores also indicate that on an average consumers feel these items are at less than agreeable level.

The same is reflected in users' perception on the four variables under study. The average mean score of Perceived usefulness and perceived ease of use is above agreeable level, whereas the average mean scores of perceived security and perceived trust is below agreeable level. Despite mixed perception on these four 
variables, users willingness to use EPS in the future is good. The average mean scores for increased EPS usage in the future remains at 4.20.

\begin{tabular}{|l|c|c|}
\hline \multicolumn{3}{|c|}{ Table: 4} \\
Descriptive Statistics on Users' Perception \\
\hline & Mean & Std. Dev. \\
\hline Perceived Usefulness & 4.14 & 0.55 \\
\hline Perceived Ease of Use & 4.03 & 0.52 \\
\hline Perceived Security & 3.78 & 0.59 \\
\hline Perceived Trust & 3.86 & 0.58 \\
\hline I will use EPS more in future & 4.20 & 0.47 \\
\hline
\end{tabular}

\section{Internal Consistency of Responses (Cronbach Alpha Test)}

The test of internal consistency of responses within the four variables was conducted using Cronbach Alpha. As any value of Cronbach alpha within 0.6 to 0.7 is assumed to acceptable and more than that is good, the calculated Cronbach alpha values for all four items, which is 0.643 , indicates acceptable level of consistency within the responses. The Cronbach alpha value for perceived usefulness and perceived ease of use is 0.762 , and for perceived security and perceived trust is 0.514. The lower consistency between the responses on perception on security and trust is mainly because of ATM fraud that happened during the survey period.

\section{Hypothesis Testing}

The hypothesis was tested by using chi square test of independence (with alpha value of 0.05). This test compared if there is significant relationship between two categorical variables. In this test, the frequency of each category for nominal variable is compared across the categories of the second nominal variable. The test results for each test also includes Cramer's V value which represents the strength of association of the two variables. Cramer's V with less than 0.10 indicates lower level of association, between 0.10 and 0.25 moderate level of association and more than 0.25 as strong associations. The summary of the hypothesis testing is presented below.

1. User Perception on Usefulness is independent by

\begin{tabular}{|l|c|c|c|c|l|}
\hline \multicolumn{1}{|c|}{ Category } & Chi Square & d.f. & P Value & Cramer's V & H0 \\
\hline Gender & 0.527 & 2 & 0.768 & 0.072 & Fail to reject \\
\hline Service Type & 13.274 & 6 & 0.039 & 0.256 & Reject \\
\hline Education & 2.880 & 6 & 0.824 & 0.119 & Fail to reject \\
\hline Income Group & 7.280 & 6 & 0.296 & 0.190 & Fail to reject \\
\hline Age Group & 4.180 & 6 & 0.652 & 0.144 & Fail to reject \\
\hline
\end{tabular}


Hypothesis testing shows that we fail to reject that users' perception on usefulness is independent by gender, education, income group and age group. Further, we reject the hypothesis that users' perception is independent by service type. This would lead to a conclusion that users' perception is independent by gender, education, income group and age group but dependent to service type.

2. User Perception on Ease of Use is independent by

\begin{tabular}{|l|c|c|c|c|c|}
\hline \multicolumn{1}{|c|}{ Category } & Chi Square & d.f. & P Value & Cramer's V & Ho \\
\hline Gender & 0.659 & 2 & 0.719 & 0.081 & Fail to reject \\
\hline Service Type & 9.943 & 6 & 0.127 & 0.222 & Fail to reject \\
\hline Education & 2.970 & 6 & 0.813 & 0.121 & Fail to reject \\
\hline Income Group & 7.482 & 6 & 0.279 & 0.192 & Fail to reject \\
\hline Age Group & 5.942 & 6 & 0.430 & 0.172 & Fail to reject \\
\hline
\end{tabular}

Hypothesis testing shows that we fail to reject the null hypothesis, which states users' perception on Ease of Use is independent by gender, service type, education, income group and age group. This leads to a conclusion that users' perception on ease of use is independent by gender, service type, education, income group.

\section{User Perception on Security is independent by}

\begin{tabular}{|l|c|c|c|c|c|}
\hline \multicolumn{1}{|c|}{ Category } & Chi Square & d.f. & P Value & Cramer's V & H0 \\
\hline Gender & 4.166 & 2 & 0.125 & 0.203 & Fail to reject \\
\hline Service Type & 4.172 & 6 & 0.653 & 0.144 & Fail to reject \\
\hline Education & 7.625 & 6 & 0.267 & 0.194 & Fail to reject \\
\hline Income Group & 6.358 & 6 & 0.384 & 0.177 & Fail to reject \\
\hline Age Group & 1.981 & 6 & 0.921 & 0.099 & Fail to reject \\
\hline
\end{tabular}

Hypothesis testing shows that we fail to reject the null hypothesis, which states users' perception on Security is independent by gender, service type, education, income group and age group. This leads to a conclusion that users' perception on security is independent by gender, service type, education, income group.

4. User Perception on Trust is independent by

\begin{tabular}{|l|c|c|c|c|l|}
\hline \multicolumn{1}{|c|}{ Category } & Chi Square & d.f. & P Value & Cramer's V & H0 \\
\hline Gender & 0.650 & 2 & 0.723 & 0.080 & Fail to reject \\
\hline Service Type & 6.536 & 6 & 0.366 & 0.180 & Fail to reject \\
\hline Education & 13.144 & 6 & 0.041 & 0.255 & Reject \\
\hline Income Group & 9.036 & 6 & 0.172 & 0.212 & Fail to reject \\
\hline Age Group & 6.537 & 6 & 0.366 & 0.180 & Fail to reject \\
\hline
\end{tabular}


The above result shows that we fail to reject the null hypothesis that states users' perception on trust is independent by gender, service type, education, income group and age group. It is thus, we can state that users' perception on trust is independent by gender, service type, education, income group.

From the above table we can conclude that perceived usefulness is not independent by service type, and perceived trust by education level. There are no sufficient evidences to reject the null hypothesis for all other association. This indicates that there is no association between the responses from all types of respondents - by gender, service type, education, income group and age group.

\section{Regression Result}

The following is the summary of the regression analysis.

\begin{tabular}{|c|c|c|c|c|c|}
\hline \multicolumn{7}{|c|}{ Table 5(a): Model Summary } \\
\hline Model & $\mathbf{R}$ & R Square & $\begin{array}{c}\text { Adjusted R } \\
\text { Square }\end{array}$ & $\begin{array}{c}\text { Std. Error of } \\
\text { the Estimate }\end{array}$ & Durbin-Watson \\
\hline 1 & .813 & .661 & .647 & .279 & 1.848 \\
\hline
\end{tabular}

The adjusted R Squared value of the model is 0.647 . The Durbin Watson test value is close to 2 .

\begin{tabular}{|l|c|c|c|c|c|}
\hline \multicolumn{7}{|c}{ Model } & $\begin{array}{c}\text { Unstandardized } \\
\text { Coefficients }\end{array}$ & $\begin{array}{c}\text { Standardized } \\
\text { Coefficients }\end{array}$ & \multirow{2}{*}{ t } & \multirow{2}{*}{ Sig. } \\
\cline { 2 - 4 } & B & Std. Error & Beta & & \\
\hline (Constant) & .339 & .287 & & 1.181 & .241 \\
\hline use & .300 & .063 & .350 & 4.734 & .000 \\
\hline easy & .352 & .062 & .389 & 5.684 & .000 \\
\hline secure & .136 & .051 & .171 & 2.670 & .009 \\
\hline trust & .178 & .056 & .221 & 3.208 & .002 \\
\hline a. Dependent Variable: INT & & & & \\
\hline
\end{tabular}

The regression result shows that all four variables are significant at 99 percent confidence interval and have positive beta coefficient indicating that an increase 
in level of response would help increase willingness for using the EPS in future. The impact of Use and Easy variable is higher than that of secure and trust variable.

\section{CONCLUSION}

The share of digital transactions against cash based transaction is quite low in Nepal. And this has been mainly due to people's reluctance in using the digital mode of transactions. Amongst the payments flows within the payments matrix, people use digital mode of payments to carryout either transfer payments or ecommerce. This study focused on users' preference for these types of transactions and the empirical results revealed that the lower level of electronic transactions can be mainly attributed to weak accessibility along with concerns for security and trust factors. There is no wider acceptance of digital mode by the merchants in the market and digital platform is not available at the time of need.

The respondents have given lower mean scores for accessibility of EPS, which indicates that there is a problem with the accessibility of EPS in the country. The lower mean score for accessibility is mainly due to disruption on the services mainly due to technical reason and or disruptions in the communication channel. Respondents have also raised their concern over system credibility. Couple of system hacks in ATM in Kathmandu during months of survey can be attributed to such a perception on the users' side.

In terms of four broader categories, respondents have given lower mean scores for perceived security and perceived trust when compared to perceived ease of use and perceived usefulness. This shows that there is a need to work on security and trust issue to strengthen users' perception towards EPS. Acceptance of the fact that EPS is secure and trustworthy would help boost users' confidence while using EPS in Kathmandu.

Empirical result shows that different items that construct user's perception are independent by gender, service type, education level, income group and age group. This result leads to a conclusion that targeted and focused intervention in the market by several such groups could help increase the usage of EPS than a common approach.

The regression result shows that all four variables are significant and have positive beta coefficient indicating that an increase in level of response would help increase willingness for using EPS in future. The impact of Use and Easy variable is higher than that of secure and trust variable. The payment service providers should therefore, focus more in making the Electronic payments services more user friendly, accessible and easier to attract users' attention. Policy makers should also give higher priority for making the electronic payment 
services more accessible, user friendly and widely acceptable in the markets, besides making them secure and trustworthy.

\section{REFERENCES}

Alhanoof Fahad Alyabes and Othman Alsalloum, 2018. "Factors Affecting Consumers' Perception of Electronic Payment in Saudi Arabia." European Journal of Business and Management Vol.10, No.27, 2018.

Alenezi, A., R., Abdulkarim, A. \& A. Veloo. 2010. “An empirical investigation into the role of enjoyment, computer anxiety, computer self-efficacy and Internet experience in influencing the students' intention to use E-learning: A case study from Saudi Arabian governmental universities." TOJET: The Turkish Online Journal of Educational Technology.

Alireza A., Yap V. C. \& M. Saravanan. 2010. "Preparation of Measurement Tools of the Effective Factors for the Acceptance of Online Stock Trading." European Journal of Economics, Finance and Administrative Sciences.

Brian Le Sar and David Porteous. 2013. "Introduction to the National Payments system." National Payments System Institute.

Committee on Payments and Settlement. 2005. "Central Bank Oversight of Payments and Settlement Systems. " Bank for International Settlement.

CPSS-IOSCO. 2012, "Principles of Financial Market Infrastructure." Bank for International Settlement.

Dilavari, A. 2018. "Impact of Demonetisation on E-Payment System." International Journal for Scientific Research \& Development Vol. 6, Issue 03, 2018.

Emrah Oney, Gizem Oksuzoglu Guven \& Wajid Hussain Rizvi. 2017. "The determinants of electronic payment systems usage from consumer' perspective." Economic Research-Ekonomska Istraživanja.

Hugh Thomas, 2013. "Measuring progress toward a cashless society." MasterCard.

Kenneth S. Rogoff. 2014, "Costs and Benefits to Phasing out Paper Currency." NBER Working Paper Series, 20126.

Loganathan D, Vignesh J, Piradeep N. and P. A. Ruban Fernaandes. 2018. "Cashless Payment System.” International Journal for Scientific Research \& Development. Vol. 6, Issue 02, 2018.

Mathema, Sushil Ram. 2005, "Payments Systems, Nepal Rastra Bank in Fifty Years." Nepal Rastra Bank.

Ministry of Finance. 2014. "Financial Sector Development Strategy." Government of Nepal. 
Nepal Rastra Bank Act, 2012 (1956).

Nepal Rastra Bank Act, 2058 (2002). 2014. "Nepal National Payment System Review" 2014. "Nepal Payment System Development Strategy"

--------------- 2014. "Review of Existing Nepal National Payments System"

-------------- 2016. "Nepal Rastra Bank: Then, Now and Ahead"

------------------ 2018. "Sixty Years of Nepal Rastra Bank" Various circulars issued by the Payments System Department.

Park, S. Y. 2009. "An Analysis of the Technology Acceptance Model in Understanding University Students' Behavioral Intention to Use e-Learning" Educational Technology \& Society, 12 (3), 150-162.

Sanghita Roy, Dr. Indrajit Sinha. 2014. "Determinants of Customers' Acceptance of Electronic Payment System in Indian Banking Sector - A Study." International Journal of Scientific \& Engineering Research, Volume 5, Issue 1, January-2014.

Subramanian, S. 2018. "Payments in India Going Digital: A Study with Reference to Credit Card Payments." Journal of Management (JOM) Volume 5, Issue 3, May-June 2018, IAEME Publications.

The World Bank (http://www.worldbank.org/en/topic/paymentsystemsremittances)

UNCDF, 2017, Payment Flow Diagnosis and Stocktaking Report for Nepal Rastra Bank (NRB) for Retail Payment Systems in Nepal, unreleased report.

Uppal, Dr. R K. 2012, "Mobile Banking and New Generation: An Indian Experience." an article compiled in Electronic Banking in India by Dr. RK Uppal, Swastik publications.

Vincent Lim Choon Seng. 2008. "The Development of E-Payments and Challenges for Central Banks in The SEACEN Countries." The SEACEN Research and Training Centre. 